\title{
Association of Mean Platelet Volume and Platelet Distribution Width with Hba1c
}

\author{
Sadikuj Jaman ${ }^{1,2, *}$, Sawgat Rezwan ${ }^{2}$, Sakibul Alam ${ }^{3}$, Rayhanul Islam ${ }^{2,4}$, Asma Ul Husna ${ }^{5}$ and Md. Abu Sayeed ${ }^{6,7}$ \\ ${ }_{1}^{1}$ Department of Lab Science Diagnostics, 153/1, Green Road, Dhanmondi, Dhaka-1205, Bangladesh \\ ${ }^{2}$ Department of Biochemistry and Molecular Biology, University of Rajshahi, Rajshahi-6205, Bangladesh \\ ${ }^{3}$ Department of pharmacy, Jahangirnagar University
}

${ }^{4}$ Lecturer, Dept. of Food Science and Technology, Henry Institute of Bioscience and Technology, Sirajganj, Bangladesh

${ }^{5}$ RMO-Cardiac surgery Square Hospitals Ltd. Dhaka, Bangladesh

${ }^{6}$ Department of Clinical and Molecular Sciences, Polytechnic University of Marche, Ancona, 60126, Italy

${ }^{7}$ Biotechnology and Microbiology Laboratory, Department of Botany, University of Rajshahi, Rajshahi-6205, Bangladesh

Received: August 28, 2017; Accepted: September 09, 2017; Published: September 30, 2017

*Corresponding author: Sadikuj Jaman, Postal address: Lab Science Diagnostics, 153/1, Green Road, Dhanmondi, Dhaka-1205, Bangladesh, Tel+8801722793579; Fax: 07136474298;E-mail: sadik09bio.ru19@gmail.com

\begin{abstract}
Diabetes mellitus type 2 (DMT2) is a metabolic disorder, and its prevalence is rising worldwide. The objective of the study was to investigate association of mean platelet volume (MPV) and platelet distribution width (PDW) with glycemic control marker HbA1c. So that MPV, PDW could be used as a prognosticators of deterioration of glucoregulation in diabetes mellitus type 2 instead of HbA1c value. This study included 87 DMT2 patients, which divided into two groups, A $(n=41$, presence in diabetics $\leq 6.5-6.9 \%)$ and B $(n=46$, target in diabetes $\geq 7.0 \%$ ), according to $\mathrm{HbA} 1 \mathrm{c}$ values. Spearsman correlation co-efficients were calculated to evaluate the relationship between MPV, PDW and HbA1c value. Binominal logistic regression analysis was performed to estimate the relationship between glycemic control, as dichotomous outcome of MPV and PDW as the main prognosticator. MPV and PDW were significantly higher in the group B compared to the group A. Significant positive correlations of MPV with Random Blood Sugar (RBS) and HbA1c value were found in the total sample. MPV and PDW correlate with glycemic control markers in DMT2 patients. In conclusion, MPV and PDW could be used as simple and cost effective prognosticators of deterioration of glucoregulation.
\end{abstract}

\section{Introduction}

Diabetic mellitus type 2 (DMT2), a metabolic disease, is the most challenging public health problem in todays world [1]. It is a complex disease characterized by insulin hormone resistance, relative lack of insulin, and high blood sugar[2,3]. According to international diabetes federation (IDF) an estimated 415 million people had diabetes worldwide in 2015 with type 2 diabetes mellitus making up about $90 \%$ of the cases [4,5]. Africa and Asia continental are living few ethnic \& races predispose people to a greater risk of developing country [5]. According to Indian continental studies indicated a threefold rise in the diabetic prevalence in rural as well as urban areas [6].
Large platelet contain dense granules are metabolically and enzymatic ally more active than smaller ones and have higher thrombotic potential. Hence, increased MPV and PDW might be linked with increased thrombotic potential [7]. Platelets are a central element of the athero-thrombotic process due to their prothrombotic and proinflamatory function[8,9,10]. The association of increased MPV, PDW and decreased platelet count with disease related to endothelial dysfunction such as metabolic syndrome diabetes, coronary artery disease (CAD) and malignancy which has been shown in many studies [11-15]. Diabetes particularly DMT2 patients are exposed to the increased platelet reactivity due to multi factorial causes such as metabolic (e.g hyperglycemia, hypertriglyceridemia) and systemic abnormalities (eg. Oxidative stress, inflammation) and insulin resistance [1619]. In diabetic thrombocytopathy, many biomarkers have been considered for the implementation in clinical practice [20]. Most parameter of platelet activity measurement is time consuming, expensive \& required high sample volume [21]. Otherwise MPV \& PDW are easy to measure of platelet size, enzymatic activity and prothrombotic potential. It can be determined by routine automated hemograms at a relatively low cost [22]. An increased of MPV is one of the risk factors for micro vascular and macro vascular complications, including cardiovascular disease (CVD), retinopathy, nephropathy occur due to chronic un control hyperglycemia in diabetics also myocardial infarction, ischemic stroke and venous thromboembolism [23-29].

HbA1c is a good marker for DMT2 patients should be kept below $6.5 \%$ in order to reduce the risk of micro \& macro vascular complications [30.] Improve glycemic control decrease mean platelet volume [31]. It can be suggested that reduce platelet activity by proper glycemic control may prevent or delay vascular complications in these patients. 
The aim of this study was to investigate association of MPV, PDW and platelet count with short term and long term glycemic control markers. So that MPV, PDW and platelet count could be used as a predictor of diabetes patients.

\section{Material \& Methods \\ Patients and Study Design}

The study was conducted in Lab science Diagnostics, (153/1, Green Road, Dhanmondi, Dhaka-1205, Bangladesh). The study included 87 diabetic patients at least 5 - 6 months duration of diabetes from 02 April 2017 to 14 July 2015. In order to reduce the impact of the confounding factors, hematological disorders, pregnancy and malignancy were factors for exclusion from the study. According to HbA1c value patients were divided into two groups: Group A ( $n=41$ HbA1c $\leq 6.5-6.9)$ and group $(n=46$ $\mathrm{HbA1c} \geq 7.0$ ). Demographic clinical and laboratory data including age, gender, complete blood cell count MPV, PDW, platelet count, fasting blood glucose (FBG), Random Blood Sugar (RBS), HbA1c and lipid profile (cholesterol, HDL, LDL and Triglycerides) in both groups were obtained.

\section{Methods}

Blood cell count and HbA1c and other parameters were measured. Blood samples were taken in tubes with EDTA anticoagulant. The tubes without anticoagulant were used for collecting blood for glucose and lipid profile measurement. Complete blood cell count was measured by sysmex XN-L series 350 (6 part). HbA1c value was measured by fine care ID chips. Lipid profile, glucose, and other biochemistry profile were measured by ERBA Mannheim XL 200 Fasting blood glucose was measured using a hexokinase method. Standardization, calibration of instrument and processing of samples were done according to manufacturer instructions. All Data reserve into MYSOFT LTD in Lab science Diagnostics. The study approval was taken from the ethics committee of Lab Science Diagnostics.

\section{Statistical Analysis}

Statistical analysis was performed by statistical packages for the social sciences (IBM SPSS Statistics) version 20 (Chicago, IL). IBM SPSS was used to find the significant difference of Fasting Blood Sugar (FBS), RBS ,HbA1c, MPV, and PDW. Spearman's correlation coefficients were calculated to evaluate the relationship between MPV, PDW with HbA1c. Binominal logistic regression analysis was performed to assess independent relationship between MPV, PDW as the main prognosticator. The cut off value of MPV and PDW was determined for optimum sensitivity and specificity ratio of the diagnostic test. Positive and negative predictive values were calculated using recommended cut off value. Data were expressed as mean \pm standard deviation. $P$ value was considered statistically significant.

\section{Result}

According to the result of sample population are detailed in (Table 1). A total of 87 patients fulfilling the selection criteria included 37 (out of $87,42.52 \%$ ) females and 50 (out of 87 , $57.47 \%$ ) males. The average age of both patients was 25 to 80 . The total number of study participants who were divided into two groups according to their diabetics status, 46 (out of $87,52.87 \%$ ) DMT2 patients were in the group B ( target in diabetics, HbA1c value $\geq 7.00$ ), 41 (out of $87,41.13 \%$ ) in the group A ( presence in diabetics, HbA1c value $\geq 7.00$ ). Statistically significant differences were observed between those groups for various parameters. We found significant differences among the groups for all examined demographic and biochemical characteristics. Median value of age, FBS, RBS, HbA1c, MPV, PDW, cholesterol, LDL, Creatinine were significantly higher in the group B compared to the group A. Except HDL, Triglycerides, Platelet count. A significantly higher MPV \& PDW value in the group B compared to group A was found $(\mathrm{P}, 0.191,0.012)$.

\begin{tabular}{|c|c|c|c|c|}
\hline Characteristics/ Parameter & DMT2 & Group $A(n=41)$ & Group $B(n-46)$ & $\mathrm{P}=$ significance \\
\hline Age (Years) & $50 \pm 12.60$ & $48(25-75)$ & $55(35-80)$ & 0.265 \\
\hline Female/Male, n (\%) & $37 / 50$ & $16 / 25$ & $21 / 25$ & 0.011 \\
\hline $\mathrm{FBG}(\mathrm{mmol} / \mathrm{L})$ & $10.8(6.1-18.9)$ & $6.9(6.1-6.85)$ & $11.65(6.8-18.9)$ & 0.255 \\
\hline $\mathrm{RBS}(\mathrm{mmol} / \mathrm{L})$ & $17.7(6.8-29.8)$ & $7.25(1.20-14.20)$ & $17.7(6.8-29.8)$ & 0.955 \\
\hline $\mathrm{HbA} 1 \mathrm{c}(\%)$ & $7.05(6.514 .90)$ & $6.60(6.5-6.9)$ & $9.1(7-14.90)$ & 0.824 \\
\hline $\mathrm{MPV}(\mathrm{fL})$ & $11.7(8.20-16.80)$ & $10.6(8.2-14.00)$ & $12.75(10.5-16.8)$ & 0.191 \\
\hline PDW (fL) & $13.8(7.9-23.8)$ & $12.5(7.9-20.8)$ & $15.7(12.2-23.8)$ & 0.012 \\
\hline Platelet count (/ccm) & $274(10-559) \times 10^{3}$ & $268(150-559) \times 10^{3}$ & $277(10-554) \times 10^{3}$ & 0.190 \\
\hline Cholesterol (mg/dl) & $195(140-310)$ & $185(140-250)$ & $206(143-310)$ & 0.140 \\
\hline $\mathrm{LDL}(\mathrm{mg} / \mathrm{dl})$ & $106.5(50-170)$ & $102(50-150)$ & $108(56-170)$ & 0.655 \\
\hline Triglycerides (mg/dl) & $209(11.5-1845)$ & $200(90-1180)$ & $198(11.5-1845)$ & 0.847 \\
\hline Creatinine $(\mathrm{mg} / \mathrm{dl})$ & $1.15(0.75-6.15)$ & $1.10(0.75-2.50)$ & $1.15(0.9-6.15)$ & 0.985 \\
\hline
\end{tabular}


Further analysis showed significant positive correlations between MPV (fL) and RBS (mmol/L) and MPV (fL) with HbA1c in figure 1, PDW (fL) with HbA1c (\%) in figure 3 in the total sample. There were no correlations individually of MPV with RBS and $\mathrm{HbA1c}$ or PDW with HbA1c in the group A or group B (Figure $1,2,3)$.

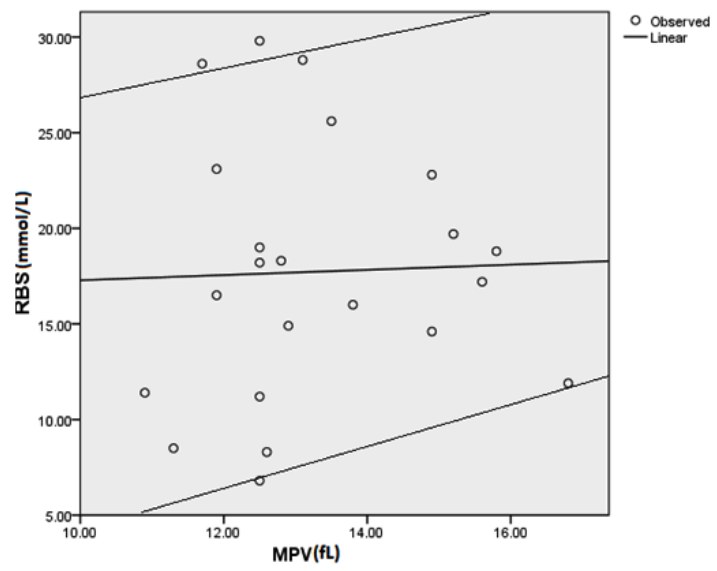

Figure 1: Correlation analysis between mean platelet volume (MPV) and Random blood sugar (RBS) levels in the total sample

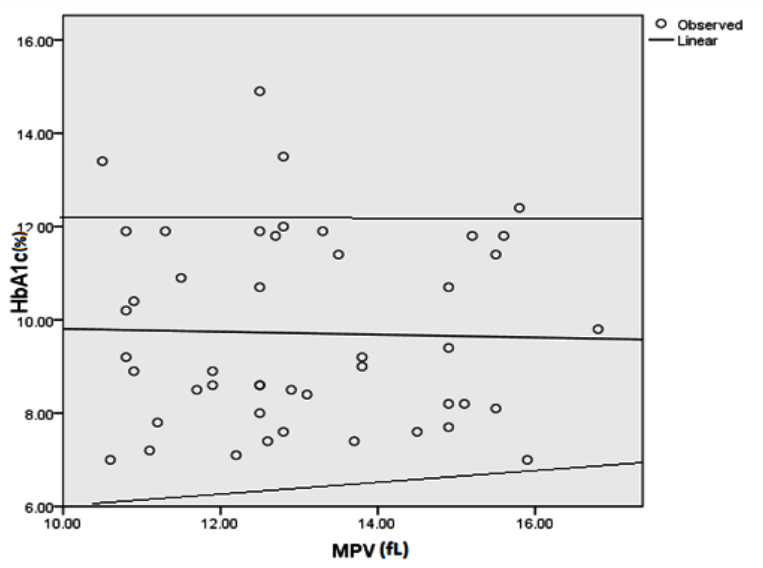

Figure 2: Correlation analysis between mean platelet volume (MPV) and glycated hemoglobin (HbA1c) levels in the total sample

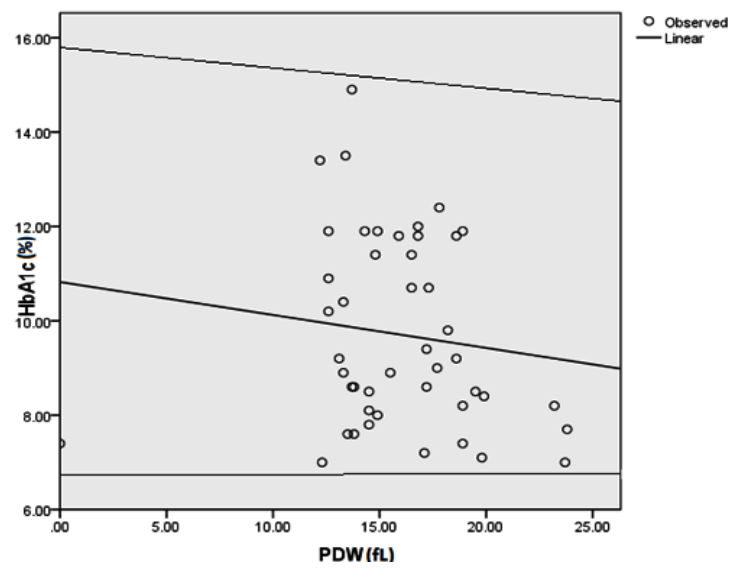

Figure 3: Correlation analysis between platelet distribution width (PDW) and glycated hemoglobin (HbA1c) levels in the total sample
Binominal logistic regression analysis model with MPV and PDW as a predictor of deterioration of glucoregulation was statically significant, (p 0.191, 0.012), Indicating that MPV distinguishes patients with good (HbA1c $\leq$ 6.5-6.9) and poor (HbA1c $\geq 7 \%$ ) glucoregulation (Table 2 ). This model showed that the significant value of MPV and PDW were positively associated with the risk of inadequate glycemic control.

Table 2: Optimal cut-off, area under curve (AUC), sensivity, specificity, Positive predicting value (PPV) and Negative predicting value (NPV) of mean platelet volume (MPV) in prognostication of glucoregulation

\begin{tabular}{|c|c|c|c|c|}
\hline Variable & $\begin{array}{c}\text { Sensitivity } \\
\text { (\%) }\end{array}$ & $\begin{array}{c}\text { Specificity } \\
\text { (\%) }\end{array}$ & $\begin{array}{c}\text { PPV } \\
\text { (\%) }\end{array}$ & $\begin{array}{c}\text { NPV } \\
\text { (\%) }\end{array}$ \\
\hline $\begin{array}{c}\text { MPV (fL) } \\
\text { (cutoff-9.55) }\end{array}$ & 85.19 & 30.30 & 58.23 & 12.50 \\
\hline $\begin{array}{c}\text { PDW (fL) } \\
\text { (cutoff- 14.55) }\end{array}$ & 45.77 & 67.86 & 75 & 37.25 \\
\hline
\end{tabular}

\section{Discussion}

Diabetic is a growing health problem associated with increased risk of micro and macro vascular complications [32]. Some parameters can easily be detected by various blood tests such as platelet count, MPV, PDW that can be used as biomarker for early detection of diabetic complication.

Several researches found platelet count was decreased in diabetic patients as compared with non diabetic patients [33]. Platelet hypersensivity is a well-known factor to the prothrombotic state in diabetics, causing increased coagulation, impaired fibrinolysis and endothelial dysfunction. Hyperactive platelet plays a critical role in the pathophysiology of the thrombotic events leading to diabetic complications [16]. MPV is a parameter used to assess platelet size and it is a potential biomarker of platelet reactivity. Already it has been shown that longer platelet is more reactive than smaller ones [22,34]. Several researches indicate positive correlation of RBS and HbA1c with MPV, PDW [31, 35]. However some studies have not shown any relation of RBS and HbA1c with Mean platelet volume [36, 37].

It was proposed that increase in MPV could be because of raised blood sugar effect to osmotic swelling and shorter life span of platelets in diabetic patients. Alternatively this may suggest that platelet activation is related to glycemic control $[38,37]$. Hyperglycemia occur non enzymatic glycation of proteins on the surface of the platelets, which decrease membrane fluidity and increase its reactivity [39]. Higher MPV responsible for increased production of young platelet due to a higher platelet turnover rate [40]. The relation between MPV and DMT2 was first reported by Sharpe and Trinick who founded a significant increase of MPV in diabetic compared with non diabetic patients [41]. This research was followed by numerous studies and with largest study conducted on 13,021 diabetic patients[14, 31, 4244]. Similarly, Our study results had shown significantly higher MPV in the group B compared to the group A. Those findings 
are mainly consistent with previous finding Besides Ozder et al. found that MPV was significantly higher in patients with HbA1c levels $\leq 7.0 \%$ than in patients with HbA1c levels $\leq 6.9$. [31,45,46] this was in consonance with the result of other studies $[43,45]$.

All of the studies listed above investigated the association of MPV and PDW with diabetic patients. [47 Obtained values indicate the possibility of using MPV, PDW as a hematological biomarker for prediction of the diabetics disease burden in terms of vascular complications. However, Data of MPV, PDW could be used as a predictor of deterioration of glucoregulation and a marker for distinguishing those patients.

Our study indicates that it might be used as a simple, effortless and cost effective prognicator of deterioration of glucoregulation. Considering that odds of inadequate glycemic control are 2 times increased per femto-liter greater MPV. Its use especially in the Lab science diagnostics could improve the screening of high risk individuals for vascular complications. Early diagnosis and appropriate treatment could thereby delay their onset or progression. Mean platelet volume can be used as a moderate quality indicator of deterioration of glucoregulation at best cut off value $9.55 \mathrm{fL}$ with sensitivity of $85.19 \%$ and specificity of $30.30 \%$. Similarly, Platelet distribution width can be used as a moderate quality indicator of glucoregulation at best cut off value $14.55 \mathrm{fL}$ with sensitivity of $45.77 \%$ and specificity of $67.86 \%$. Finally it can be concluded that MPV \& PDW are not substitute for HbA1c but it can be replace it in the circumstances of limited testing availability or limited financial resources. Due to small sample size and few in number of patient in a same area like Dhaka are considered as two limitation of this study. This study supports gluco metabolic state, poor glycemic control and platelet activity as measured by MPV and PDW. So, the study suggests that MPV, PDW and platelet count could be used as a cost effective tool to monitor diabetic mellitus.

\section{Conclusion}

We all are aware of the risk factors for diabetic complications such as duration, glycemic control and dyslipidemia. We found increase in MPV, PDW and decrease platelet count in diabetic patients whose HbA1c value was 7 or more. This implies that raised MPV and PDW can be considered as biomarkers for early detection of impending complication instead of HbA1c value. Also we found that this platelet parameter were more significant in micro vascular complications as compared to macro vascular complications.

\section{Acknowledgements}

The authors would like to thanks Lab Science diagnostic for sharing patients report

\section{Conflicts of Interest}

There are no conflicts of interest

\section{References}

1. Adeghate E, Schattner P, Dunn E. An update on the etiology and epidemiology of diabetes mellitus. Ann N Y Acad Sci. 2006;1084:129. Doi: $10.1196 /$ annals.1372.029

2. Powers AC. Diabetes mellitus. In: Longo DL, Fauci AS, Kasper DL, Hauser SL, Jameson JL, Loscalzo J, editors. Harrison's Principles of Internal Medicine. 18th ed. New York: McGrawHill; 2012.

3. Faghilimnai S, Hashemipour M, Kelishadi B. The lipid profile of children with type 1 diabetes as compared to the controls. ARYA J. 2006;2(1):36-38.

4. International Diabetes Federation. IDF Diabetes Atlas 7th edition. 2015;IDF;13.

5. Manu A, Shyamal K, Sunil G, Sandhu JS. A study on the lipid profile and the body fat in patients with diabetes mellitus. Anthropologist. 2007;4:295-298.

6. Mohan V, Deepa M, Deepa R, Shanthirani CS, Farooq S, Ganesan A ,et. al. Secular trends in the prevalence of diabetes and impaired glucose tolerance in urban south India - The Chennai urban rural epidemiology study (CURES-17). Diabetologia. 2006;49:1175-1178. Doi: $10.1007 /$ s00125-006-0219-2

7. Endler G, Klimesch A, Sunder-Plassmann H, Schillinger M, Exner $\mathrm{M}$, Mannhalter $\mathrm{C}$, et al. Mean platelet volume is an independent risk factor for myocardial infarction but not for coronary artery disease. Br J Haematol. 2002;117(2):399-404. Doi: 10.1046/j.13652141.2002.03441.x

8. Jindal S, Gupta S, Gupta R, Kakkar A, Singh HV, Gupta K, et al. Platelet indices in diabetes mellitus: indicators of diabetic microvascular complications. Hematology 2011; 16:86-9. Doi: 10.1179/10245331 1X12902908412110

9. Kubisz P, Stančiaková L, Staško J, Galajda P, Mokáň M. Endothelial and platelet markers in diabetes mellitus type 2. World J Diabetes 2015;6(3):423-31. Doi: 10.4239/wjd.v6.i3.423

10. Kaplan ZS, Jackson SP. The role of platelets in atherothrombosis. Hematology Am Soc Hematol Educ Program. 2011;2011:51-61. Doi: 10.1182/asheducation-2011.1.51

11. Aypak C, Türedi O, Bircan MA, Yüce A. Could mean platelet volume among complete blood count parameters be a surrogate marker of metabolic syndrome in pre-pubertal children? Platelets. 2014;25(6):393-398. Doi: 10.3109/09537104.2013.827783

12. Li JY, Li Y, Jiang Z, Wang RT, Wang XS. Elevated mean platelet volume is associated with presence of colon cancer. Asian Pac J Cancer Prev. 2014;15(23):10501-10504.

13. Li S, Zhu CG, Guo YL, Xu RX, Zhang Y, Sun J, et al. The relationship between the plasma PCSK9 levels and platelet indices in patients with stable coronary artery disease. J Atheroscler Thromb. 2015;22(1):76-84. Doi: 10.5551/jat.25841

14. Zaccardi F, Rocca B, Pitocco D, Tanese L, Rizzi A, Ghirlanda G. Platelet mean volume, distribution width, and count in type 2 diabetes, impaired fasting glucose, and metabolic syndrome: A meta-analysis. Diabetes Metab Res Rev. 2015;31(4):402-410. doi: 10.1002/ dmrr.2625

15. Ergelen M, Uyarel H. Plateletcrit: A novel prognostic marker for acute coronary syndrome. Int J Cardiol. 2014;177(1):161. DOI: $10.1177 / 1479164110383994$ 
16. Ferreiro JL, Gómez-Hospital JA, Angiolillo DJ. Platelet abnormalities in diabetes mellitus. Diab Vasc Dis Res. 2010; 7(4):251-259. Doi: $10.1177 / 1479164110383994$

17. Schneider DJ. Factors contributing to increased platelet reactivity in people with diabetes. Diabetes Care 2009; 32(4):525-527. Doi: 10.2337/dc08-1865

18. Kakouros N, Rade JJ, Kourliouros A, Resar JR. Platelet function in patients with diabetes mellitus: from a theoretical to a practical perspective. Int J Endocrinol. 2011;2011:742719. Doi: 10.1155/2011/742719

19. Vinik AI, Erbas T, Park TS, Nolan R, Pittenger GL. Platelet dysfunction in type 2 diabetes. Diabetes Care. 2001; 24(8):1476-1485. Doi: 10.2337/diacare.24.8.1476

20. Kubisz P, Stančiaková L, Stasko J, Galajda P, Mokáň M. Endothelial and platelet markers in diabetes mellitus type 2. World J Diabetes. 2015;6(3):423-431. Doi: 10.4239/wjd.v6.i3.423

21. Michelson AD. Methods for the measurement of platelet function. Am J Cardiol. 2009;103(3 Suppl):20-26. Doi: 10.1016/j. amjcard.2008.11.019

22. Chu SG, Becker RC, Berger PB, Bhatt DL, Eikelboom JW, Konkle $\mathrm{B}$, et al. Mean platelet volume as a predictor of cardiovascular risk: a systematic review and meta-analysis. J Thromb Haemost. 2010;8(1):148-156. Doi: 10.1111/j.1538-7836.2009.03584.x

23. Folli F, Corradi D, Fanti P, Davalli A, Pae A, Giaccari A, et al. The role of oxidative stress in the pathogenesis of type 2 diabetes mellitus micro and macro-vascular complications: avenues for a mechanistic based therapeutic approach. Curr Diabetes Rev. 2011;7(5):313-324.

24. Buch A, Kaur S, Nair R, Jain A. Platelet volume indices as predictive biomarkers for diabetic complications in Type 2 diabetes patients. J Lab Physicians. 2017;9(2):84-88. Doi: 10.4103/0974-2727.199625

25. Kiliçli-Camur N, Demirtunç R, Konuralp C, Eskiser A, Başaran Y. Could mean platelet volume be a predictive marker for acute myocardial infarction. Med Sci Monit. 2005;11(8):387-392.

26. Khandekar MM, Khurana AS, Deshmukh SD, Kakrani AL, Katdare $\mathrm{AD}$, Inamdar AK. Platelet volume indices in patients with coronary artery disease and acute myocardial infarction: an Indian scenario. J Clin Pathol 2006;59(2):146-149. Doi: 10.1136/jcp.2004.025387

27. Bath P, Algert C, Chapman N, Neal B; PROGRESS Collaborative Group. Association of mean platelet volume with risk of stroke among 3134 individuals with history of cerebrovascular disease. Stroke. 2004;35(3):622-626. Doi: 10.1161/01.STR.0000116105.26237

28. Braekkan SK, Mathiesen EB, Njølstad I, Wilsgaard T, Størmer J, Hansen JB. Mean platelet volume is a risk factor for venous thromboembolism: the Troms $\emptyset$ Study, Troms $\emptyset$, Norway. J Thromb Haemost. 2010;8(1):157-162. Doi: 10.1111/j.15387836.2009.03498.x

29. Han JY, Choi DH, Choi SW, Kim BB, Ki YJ, Chung JW, Koh YY, Chang KS, Hong SP. Stroke or coronary artery disease prediction from mean platelet volume in patients with type 2 diabetes mellitus. Platelets. 2013;24(5):401-406. Doi: 10.3109/09537104.2012.710858

30. Skyler JS, Bergenstal R, Bonow RO, Buse J, Deedwania P, Gale EA, et al. Intensive glycemic control and the prevention of cardiovascular events: implications of the ACCORD, ADVANCE, and VA diabetes trials: a position statement of the American Diabetes Association and a scientific statement of the American College of Cardiology Foundation and the American Heart Association. Circulation. 2009;32(1):187-192. Doi: 10.1161/CIRCULATIONAHA.108.191305

31. Demirtunc R, Duman D, Basar M, Bilgi M, Teomete M, Garip T. The relationship between glycemic control and platelet activity in type 2 diabetes mellitus. J Diabetes Complications. 2009;23(2):89-94. Doi: 10.1016/j.jdiacomp

32. Dindar S, Cinemre H, Sengul E, Annakkaya AN. Mean platelet volume is associated with glycaemic control and retinopathy in patients with type 2 diabetes mellitus. West Indian Med J. 2013;62(6):51923. Doi: $10.7727 /$ wimj.2012.284

33. Meisinger C, Ruckert I, Stockl D, Thorand B, Peters A, Kowall B, et al. Hematological parameters and pre diabetes and diabetes in adults from the general population. J Diabetes Metab. 2014;5:335. Doi: 10.4172/2155-6156.1000335

34. Martyn CN, Matthews DM, Popp-Snijders C, Tucker J, Ewing DJ, Clarke BF. Effects of sorbinil treatment on erythrocytes and platelets of persons with diabetes. Diabetes Care. 1986;9(1):36-39.

35. Shah B, Sha D, Xie D, Mohler ER, 3rd, Berger JS. The relationship between diabetes, metabolic syndrome, and platelet activity as measured by mean platelet volume: The National Health and Nutrition Examination Survey, 1999-2004. Diabetes Care. 2012;35(5):1074-1078. Doi: 10.2337/dc11-1724

36. Unubol M, Ayhan M, Güney E. The relationship between mean platelet volume with micro albuminuria and glycemic control in patients with type II diabetes mellitus. Platelets. 2012;23(6):475480 Doi: 10.3109/09537104.2011.634934

37. Bavbek N, Kargili A, Kaftan O, Karakurt F, Kosar A, Akcay A. Elevated concentrations of soluble adhesion molecules and large platelets in diabetic patients: Are they markers of vascular disease and diabetic nephropathy? Clin Appl Thromb Hemost. 2007;13(4):391-397. Doi: 10.1177/1076029607303615

38. Coban E, Bostan F, Ozdogan M. The mean platelet volume in subjects with impaired fasting glucose. Platelets. 2006;17(1):67-69. DOI: $10.1080 / 09537100500220729$

39. Winocour PD, Watala C, Kinlough-Rathbone RL. Membrane fluidity is related to the extent of glycation of proteins, but not to alterations in the cholesterol to phospholipid molar ratio in isolated platelet membranes from diabetic and control subjects. Thromb Haemost. 1992;67(5):567-571.

40. Guthikonda S, Alviar CL, Vaduganathan M, Arikan M, Tellez A, DeLao $\mathrm{T}$, et al. Role of reticulated platelets and platelet size heterogeneity on platelet activity after dual anti platelet therapy with aspirin and clopidogrel in patients with stable coronary artery disease. J Am Coll Cardiol 2008;52(9):743-749. Doi: 10.1016/j.jacc.2008.05.031

41. Sharpe PC, Trinick T. Mean platelet volume in diabetes mellitus. Q J Med. 1993;86(11):739-742. Doi: 10.4103/0974-2727.98662

42. Papanas N, Symeonidis G, Maltezos E, Mavridis G, Karavageli E, Vosnakidis T, Lakasas G. Mean platelet volume in patients with type 2 diabetes mellitus. Platelets. 2004;15(8):475-478. Doi: 10.1080/0953710042000267707

43. Kodiatte TA, Manikyam UK, Rao SB, Jagadish TM, Reddy M, Lingaiah HK, Lakshmaiah V. Mean platelet volume in Type 2 diabetes mellitus. J Lab Physicians. 2012;4(1):5-9. Doi: 10.4103/0974-2727.98662 
44. Shah B, Sha D, Xie D, Mohler ER 3rd, Berger JS. The relationship between diabetes, metabolic syndrome, and platelet activity as measured by mean platelet volume: the National Health and Nutrition Examination Survey, 1999-2004. Diabetes Care 2012;35(5):1074-1078. Doi: 10.4103/0974-2727.98662

45. Dindar S, Cinemre H, Sengul E, Annakkaya AN. Mean platelet volume is associated with glycaemic control and retinopathy in patients with type 2 diabetes mellitus. West Indian Med J. 2013;62(6):519523. Doi: $10.7727 /$ wimj.2012.284
46. Ozder A, Eker HH. Investigation of mean platelet volume in patients with type 2 diabetes mellitus and in subjects with impaired fasting glucose: a cost effective tool in primary health care? Int J Clin Exp Med. 2014;7(8):2292-2297.

47. Jagroop IA, Tsiara S, Mikhailidis DP. Mean platelet volume as an indicator of platelet activation: methodological issues. Platelets. 2003;14(5):335-336. Doi: 10.1080/095371002220148332 